\title{
The effects of simulated rainfall on immature population dynamics of Aedes albopictus and female oviposition
}

\author{
Hamady Dieng • G. M. Saifur Rahman • A. Abu Hassan • M. R. Che Salmah • \\ Tomomitsu Satho $\cdot$ Fumio Miake $\cdot$ Michael Boots $\cdot$ AbuBakar Sazaly
}

Received: 19 May 2010 / Revised: 7 January 2011 / Accepted: 7 January 2011 / Published online: 27 January 2011

(C) ISB 2011

\begin{abstract}
Larvae of Aedes albopictus Skuse typically inhabit natural and artificial containers. Since these larval habitats are replenished by rainfall, Ae. albopictus may experience increased loss of immature stages in areas with high levels of rainfall. In this study, we investigated the effects of rainfall and container water level on population density, and oviposition activity of Ae. albopictus. In field and laboratory experiments, we found that rainfall resulted in the flushing of breeding habitats. Excess rain negatively impacted larval and pupal retention, especially in small habitats. When filled with water to overflowing, container habitats were significantly repellent to ovipositing females. Taken together, these data suggest that rainfall triggers population loss of Ae. albopictus and related species through a direct detrimental effect (flushing out) and an indirect effect (ovipositional repellency).
\end{abstract}

Keywords Aedes albopictus · Container · Rainfall · Population loss $\cdot$ Repellency

H. Dieng $(\bowtie) \cdot$ G. M. S. Rahman • A. Abu Hassan •

M. R. Che Salmah

School of Biological Sciences, Universiti Sains Malaysia, 11800, Penang, Malaysia

e-mail: hamachan1@yahoo.com

T. Satho $\cdot$ F. Miake

Faculty of Pharmaceutical Sciences, Fukuoka University, Fukuoka, Japan

M. Boots

Department of Animal and Plant Sciences,

University of Sheffield,

Sheffield, UK

A. Sazaly

Department of Medical Microbiology, University of Malaya, Kuala Lumpur, Malaysia

\section{Introduction}

A special characteristic of Aedes mosquitoes is that their eggs require the retention of enough moisture for successful embryonation (Strickman 1980; Hill et al. 2006). This is typical of Ae. albopictus, a species that is increasingly attracting major public health attention. The species has the innate ability to transmit dengue viruses (Shroyer 1986; Mitchell 1991; Gratz 2004; Malavige et al. 2004) which infect up to 50 million people every year, causing more than 20,000 deaths globally (Burke and Monath 2001; WHO http://www.who.int/topics/dengue/en/). Several other pathogens (Konishi 1989; Mitchell et al. 1998) including Chikungunya virus (Roiz et al. 2009; Delatte et al. 2010) are also transmitted by this vector, which has been proven to be a particularly invasive species (Hawley 1988).

Due to the importance of Ae. albopictus in public health, a substantial body of works has been directed towards understanding its population dynamics. The larvae of this mosquito typically develop in various aquatic habitats, including phytotelmata and artificial containers (Hawley 1988; Sota et al. 1992; Madon et al. 2003; Simard et al. 2005). The prevalence of the larvae in these habitats depends largely on rainfall, which is therefore the major water source (Fish and Carpenter 1982). Although evidence exists that rainfall is responsible for the abundance of $A e$. albopictus (Lo and Narimah 1984), heavy rains have negative effects on the egg population (Hornby et al. 1994). It seems likely that there is a trade-off between sufficient rainfall and habitat population. This is because heavy rainfall could create new habitats and the overflowing of existing ones, which may wash out the larvae, thus off-setting their quality in older habitats.

In spite of previous suggestions addressing the negative impacts of rainfall on the eggs (Rozilawati et al. 2007) and 
immature stages (Foo et al. 1985) of dengue vectors, no research has focused attention on addressing the significance of rainfall as a mortality factor. A few experiments have demonstrated the effects of rainfall on mosquito larvae. Paaijmans et al. (2007) reported that immature populations of malaria mosquitoes suffer high losses during rainfall events, but the authors did not take into consideration the pupal stage, which is known to dwell mostly on the water surface and small habitats; factors that are important in mosquito productivity (Hawley 1988). In another study on container-breeding mosquitoes, Koenraadt and Harrington (2008) showed the effects of rain on Ae. albopictus and $C x$. pipiens populations, but this investigation involved only heavy rains. Therefore, there is little analysis on the significance of the intensity of rainfall on Ae. albopictus larval performance and female oviposition.

As in most Aedes species, a particular characteristic of Ae. albopictus is that the females deposit eggs preferentially on the wet walls of container habitats (Hawley 1988), at sites where there has been standing water previously (Hill et al. 2006) and where flooding will likely to occur at some time in the future (Hill et al. 2006; Clements 1963). The container water level may vary with rainfall. At these sites delimitated by a varying waterline, the newly laid eggs must retain enough moisture for successful embryonation (Strickman 1980; Hill et al. 2006). Clearly, the presence of the waterline is critical to the increase in population of such mosquitoes. Surprisingly, the role of waterline as it affects population dynamics of Aedes mosquitoes remains largely unexplored. Here, we investigated the effects of rainfall on Ae. albopictus over its larval development, habitat quality and oviposition responses.

\section{Materials and methods}

\section{Site of study}

The study was carried out in the premises of the Universiti Sains Malaysia, located to the northeast of Penang Island. The premise is near to a wooded peridomestic area, with many trees such Mischelia champaca, Mischelia figo, Mangifera indica and various herbaceous plants. The area is surrounded by administrative buildings including classrooms, many car parking sites, and cafeterias. It is also an open area that receives high amounts of rainfall. Such conditions are typically ideal for the breeding of $A e$. albopictus. A preliminary survey revealed that containers such as tin cans, flower vases, bottles, trays, plastic bowls, paint cans, broken ceramics, buckets and bucket covers represent the main breeding sites. No tree hole was found in the area. Ae. albopictus makes up the great majority of the mosquito fauna (Fig. 1).

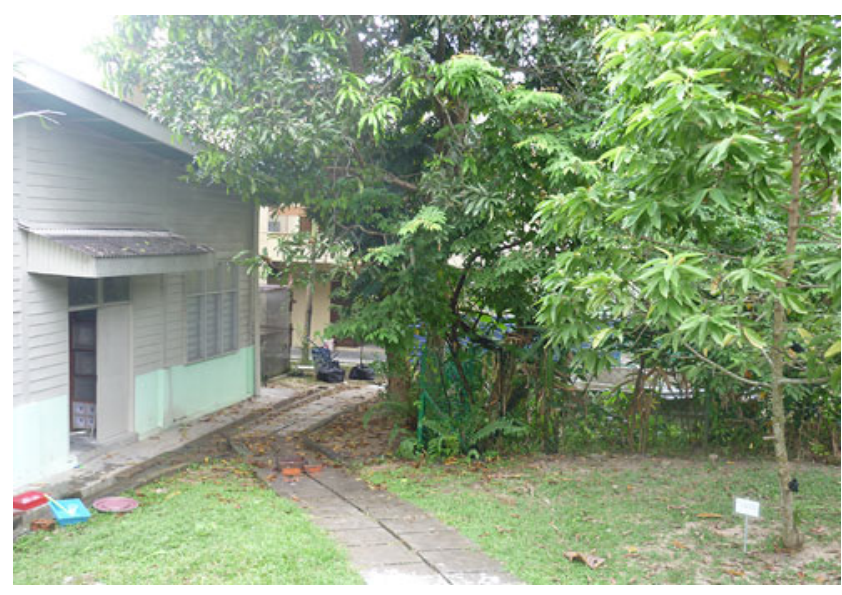

Fig. 1 Study site

Mosquito rearing

The Ae. albopictus colony used in this study was collected as pupae from outdoor containers in 2009 in Penang Island (between latitude $5^{\circ} 8^{\prime} \mathrm{N}-5^{\circ} 35^{\prime} \mathrm{N}$ and longitude $100^{\circ} 8^{\prime} \mathrm{E}-$ $100^{\circ} 32^{\prime} \mathrm{E}$ ) (Ahmad et al. 2006) and maintained at $29 \pm 3^{\circ} \mathrm{C}$, $75 \pm 10 \%$ humidity and photoperiod $13: 10 \mathrm{~h}, 1 \mathrm{~h}$ of dusk in the insectary of the School of Biological Sciences, Universiti Sains Malaysia. Emerging adults were kept in standard mosquito rearing cages $(30 \mathrm{~cm} \times 30 \mathrm{~cm} \times 30 \mathrm{~cm}$, length $\times$ breadth $\times$ height) and provided with a $10 \%$ glucose solution. Approximately $2-3$ days after eclosion, females were blood-fed on restrained mice. Gravid females were given the opportunity to lay eggs in oviposition devices. An oviposition device corresponds to a $300 \mathrm{~mL}$ capacity plastic container (height $7 \mathrm{~cm}$, upper diameter $9 \mathrm{~cm}$, lower diameter $5.5 \mathrm{~cm}$ ) half-filled with tap water and lined with an oviposition substrate $(3.5 \mathrm{~cm} \times 25 \mathrm{~cm}$ piece of filter paper, Whatman ${ }^{\circledR} \# 1$; Whatman International, Maidstone, UK). Subsequently, eggs were dried under insectary conditions and kept as stock colonies.

The production of experimental gravid females and immature stages

To routinely obtain experimental gravid females, eggs from the egg bank were hatched in cool boiled tap water in accordance with the procedure previously described elsewhere (Dieng et al. 2006). Larval feeding was standardized to avoid variability in larval populations; 100 larvae were fed $2.5 \mathrm{~g}$ dried yeast at eclosion and on day 4 post-eclosion. The resulting adults were kept in cages and fed $10 \%$ glucose solution from a cotton wick. Two days after emergence, females were offered blood meals from restrained mice. To routinely obtain experimental larvae and pupae, samples from the stored eggs were hatched in deionized water and the eclosed larvae were reared following Dieng et al. (2002). 
Mimics of natural habitats of Ae. albopictus using plastic containers

In northern peninsular Malaysia, Ae albopictus uses a variety of artificial containers that collect rainwater as habitats (Zakaria et al. 2009). This mosquito is an opportunistic container user, which can utilize both natural and artificial container habitats. It has the ability to acclimate to a wide range of confined water bodies and to develop in very small collections of water (Hawley 1988; Dieng et al. 2007). In Penang, the habitats frequently infested by Ae. albopictus include plastic containers of diverse sizes. Here, we used two types of disposable plastic cups: a large one $(5.5 \mathrm{~cm} \times 7 \mathrm{~cm} \times 9 \mathrm{~cm}$, capacity $300 \mathrm{~mL})$ and a small one $(5 \mathrm{~cm} \times 2.5 \mathrm{~cm} \times 6 \mathrm{~cm}$, capacity $60 \mathrm{~mL})$. These containers are pertinent mimics of those encountered in nature.

Obtaining simulated rains

Penang is an equatorial state and receives heavy rainfall during the rainy season, with annual rainfall varying from 2,000 to $2,500 \mathrm{~mm}$ (Ahmad et al. 2006). To mimic this natural pattern simulated, rainfall was produced as shown in Fig. 2. Water flow from the tap water was channeled to a shower head (Techplas, Malaysia), using a PVC pipe $(1.5 \mathrm{~cm})$. The shower head used in this experiment had the following characteristics: round shaped, diameter of $9 \mathrm{~cm}$ and containing 60 holes. The distal part of the pipe holding the shower head was hung on a wooden support at a height of $10 \mathrm{~m}$. The shower head was directed upward, such that the water flow from the shower was released as rain drops. The shower head was adjusted so that the vast majority of raindrops fell within the approximate surface area of $1 \mathrm{~m}^{2}$. Preliminary trials showed that the intensity at which the jets of water were ejected from the holes of the shower head depended on the degree to which the valves of the tap were opened. We also observed that the quantity of water runoff resulting from the rain shower was a function of time. Based on this information, we used two rainfall regimes: (1) tap valves were one-quarter open $\left(90^{\circ}\right.$ to the vertical or "off" position for $10 \mathrm{~min}$ and (2): tap valves were fully open $\left(360^{\circ}\right)$ to the vertical or "off" position for $25 \mathrm{~min}$. Two sets each of 20 replicates of both small and large containers were exposed to each of the rainfall regimes.
Fig. 2 Experimental design. Tap water $(A)$ is connected to a PVC pipe $(B)$, which is connected to the shower tap water $(C)$. The boxes indicate the opening directions and opening intensities of the taps
A. Tap water and opening

B. PVC pipe

PVC pipe - shower head connection

The opening of tap valves
Tap valves were $1 / 4$ open $\left(90^{\circ}\right) / 10 \mathrm{~min}$

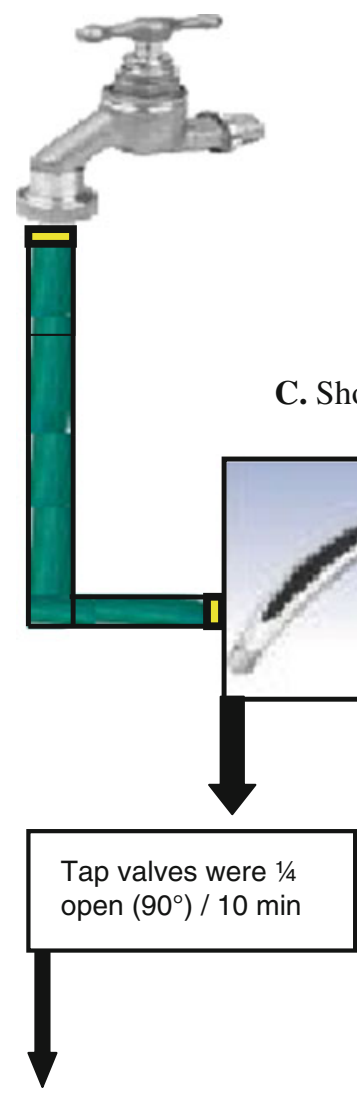

Regime 1
Regime 2

Artificial rains

Tap valves were fully open $\left(360^{\circ}\right)$ / $25 \mathrm{~min}$ 


\section{Experiments}

Simulated rainfall and developing stages of Ae. albopictus

To assess the effects of rainfall on immature stages of $A e$. albopictus, two rainfall intensity regimes (regime 1 and regime 2) were evaluated against second, third and fourth instar larvae and pupae in large plastic containers in the field. Each container contained 50 larvae of same stage The number of replicates of containers for each developing stage was either 8 or 10 . All containers were placed in a tray. Eight test tubes $(2.3 \mathrm{~cm} \times 15 \mathrm{~cm})$ placed at the same height above the ground level and at the vicinity of the experimental containers were used as gauges to measure rainfall. The quantity of rainfall was measured by the conventional method of rain gauge. It was calculated (in $\mathrm{mm}$ ) using the formula: $\mathrm{h}=\mathrm{V} / \pi * R^{2}$, where $\mathrm{V}$ is the volume of water $(\mathrm{mL})$ collected on the surface area of the opening of the glass tube, $\pi=3.14$, and $R$ is the radius of the glass tube's opening. In order to assess the effect of rainfall on the larvae in different sized containers, the experiment was repeated using small containers. In this experiment, the numbers of immature stages removed from both large and small containers were counted after rainfall. In the text, we considered second instar larvae (L2) as young, while the third and fourth developmental stages (L3-L4) were considered as old larvae.

\section{Water level and oviposition responses of Ae. albopictus}

This experiment was carried out to examine the effects of water level on the oviposition responses of Ae. albopictus. A total of 20 gravid females were placed in a cage holding $10 \%$ glucose solution source and four oviposition cups. Two cups were filled with water to overflowing and the remaining two were half-filled. A circular piece of cardboard box, with a diameter of $24 \mathrm{~cm}$ was placed at the middle of the oviposition cage. On the circle were delimited four circles (diameter $8 \mathrm{~cm}$ ) so that each circle was of equal distance from the nearest circle. The four oviposition cups were placed on these circles as shown in Fig. 3. This experiment was replicated four times with one positioning of the four cups corresponding to one replicate. After a 24-h oviposition period, the numbers of eggs laid in each cup were counted and recorded.
Fig. 3 Oviposition bioassay design. The two positions of the two types of containers scored one oviposition bioassay replicate

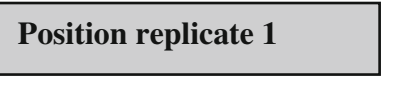

$10 \%$ sugared cotton wick

Circular piece of cardboard box

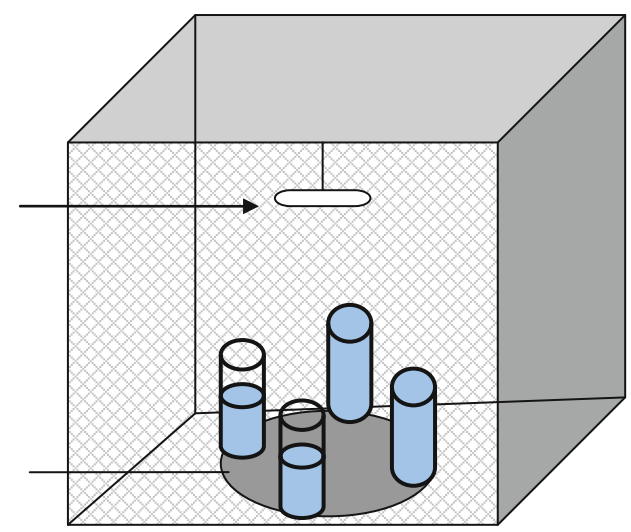

\section{Position replicate 2}

Half-filled container

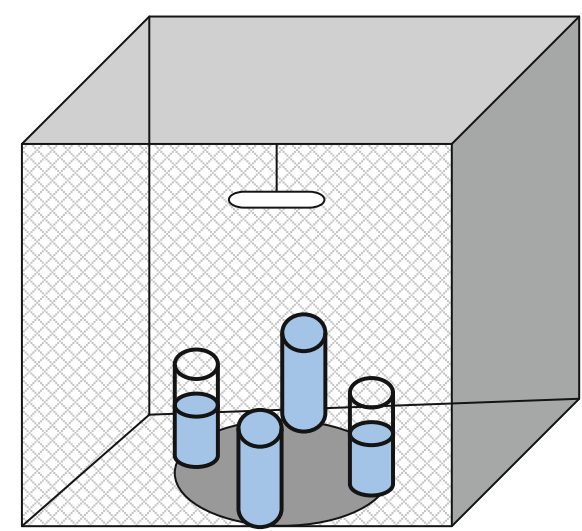

Fully-filled container 


\section{Data collection and analysis}

In the first experiment, the numbers of immature stages removed from both large and small containers were counted after the simulated rainfalls. In the second experiment, eggs laid were counted by inspecting oviposition substrates under a dissecting microscope (Meiji EMZ; Meiji Techno, Tokyo, Japan). We considered the rate of removal of larvae and pupae to be the number individuals flushed out divided by the initial number of individuals. We evaluated the effects of rainfall intensity regime on immature stages by comparing the flushing out patterns of immature stages due to the light and heavy rainfalls for each container size. The effects of container size on immature stage due to rainfall were determined by comparing the flushing out profiles from large and small containers. The numbers of eggs laid on oviposition substrates and on water surface were scored as oviposition responses. Comparisons were performed by analysis of variance from the SYSTAT ${ }^{\circledR} 13$ statistical software package (Systat 2009).

\section{Results}

\section{Experimental rains}

The rainfall quantity was significantly $(F=54.52, \mathrm{df}=1, P<$ 0.001 ) higher during the second regime than during the first regime. Based on this evidence, we considered the regime 2 rain as "heavy rainfall (HRF)" and regime 1 as "light rainfall (LRF)" (Table 1).

Effects of rainfall on developing stages of Ae. albopictus

Under LRF, all developing stages were flushed out from the large containers, but in small numbers. In the small containers (SC), however, only young larvae were ejected during LRF. There was no significant difference between the rates of ejection of Ae. albopictus from SC and large containers (LC) (young larvae: $\mathrm{F}=2.14, \mathrm{df}=1$, $P=0.160$; old larvae: $\mathrm{F}=2.25, \mathrm{df}=1, P=0.151$; pupae: $\mathrm{F}=$ $2.25, \mathrm{df}=1, P=0.151)$. Under HRF, all developing stages were flushed out from all the containers, but at greater rates by far from SC. Significant differences were noted between the rates of flushing out of Ae. albopictus from SC and LC (young larvae: $\mathrm{F}=53.28, \mathrm{df}=1, P<0.001$; old larvae: $\mathrm{F}=49.63, \mathrm{df}=1, P<0.001$; pupae: $\mathrm{F}=11.02, \mathrm{df}=1$, $P=0.004)$. In both container types, ejection rate of all developmental stages increased with rainfall intensity. In $\mathrm{LC}$, the rate of flushing out of young larvae did not differ statistically between the two rain intensities $(\mathrm{F}=4.04, \mathrm{df}=$ $1, P=0.059$ ), but was numerically higher during HRF. The rates of flushing out were significantly higher during HRF for both old larvae $(\mathrm{F}=8.03, \mathrm{df}=1, P=0.011)$ and the pupal stage $(\mathrm{F}=14.44, \mathrm{df}=1, P=0.001)$. The patterns of flushing out from SC were similar to those observed in LC. Significantly, the rates of flushing out of young larvae $(\mathrm{F}=88.29, \mathrm{df}=1, P<0.001)$, old larvae $(\mathrm{F}=75.24, \mathrm{df}=1$, $P<0.001)$ and pupae $(\mathrm{F}=27.15, \mathrm{df}=1, P<0.001)$ were higher by far during HRF than LRF (Fig. 4). Clearly, rainfalls result in the loss of the immature stages of $A e$. albopictus and this effect was stronger during HRF.

Effects of water level on oviposition responses of $A e$. albopictus

The mean number of eggs deposited by Ae. albopictus varied significantly with container water level $(\mathrm{F}=16.88, \mathrm{df}=4, P<$ $0.05)$. The oviposition response was significantly greater in half-filled containers than in those filled to overflowing (Fig. 5).

\section{Discussion}

Mosquito larvae and pupae live in water and reach the airwater interface from time to time to obtain oxygen (Paaijmans et al. 2007). During rains, rain drops hit the water surface of containers, thus splashing some water away from the containers. With splashing water, the larvae and pupae present in the container could be swept out. During container flushing, immature stages may be carried over the edge of the container while attached (via the larval siphon or pupal trumpets) to the water surface. This is more prominent
Table 1 Characteristics of the artificial rainfalls used in this study. Mean values with the same lower case letter do not show a significant difference $(P<0.05)$ based on ANOVA

\begin{tabular}{lll}
\hline & Regime 1 & Regime 2 \\
\hline Tap valves & One-quarter opened $\left(90^{\circ}\right)$ & Fully opened $\left(360^{\circ}\right)$ \\
Duration (min) & 10 & 25 \\
Replicates & 20 & 20 \\
Rainfall quantity (mm) & $6.28 \pm 0.61$ a & $62.45 \pm 7.58 \mathrm{~b}$ \\
Range & $4.3-9.1$ & $15.6-84.3$ \\
Characterization & Light & Heavy \\
\hline
\end{tabular}


Fig. 4 Mean $( \pm \mathrm{SE})$ percentage of Aedes albopictus flushed out from containers under heavy and light rainfalls. $Y$ Young larvae (second stages), $O$ old larvae (third and fourth stages), $P$ pupae. Bar charts with the same letter or number do not show a significant difference $(P<0.05)$ based on Tukey's test

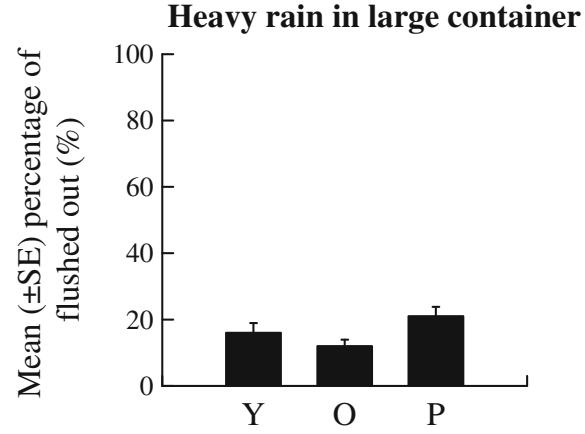

Light rain in large container
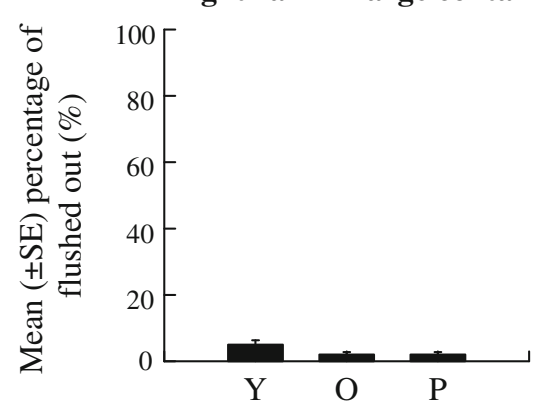

Developmental stage
Heavy rain in small container

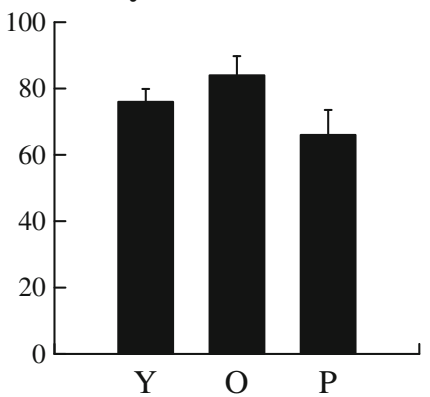

Light rain in small container

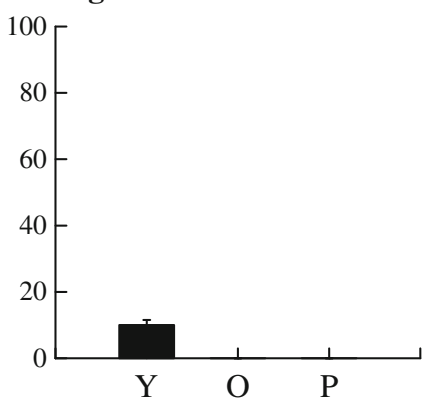

Developmental stage during strong rains, which have larger and more frequent raindrops than light rain. Therefore, rainfall could have direct and negative effects on the number of larvae and pupae in the containers.

Furthermore, rains may also affect the fitness of the container for breeding mosquito larvae and pupae. During heavy rains, the nutrients in the container habitat may be lost with the splashing water, making the container habitat impoverished of food resources for the larvae (Dieng et al.

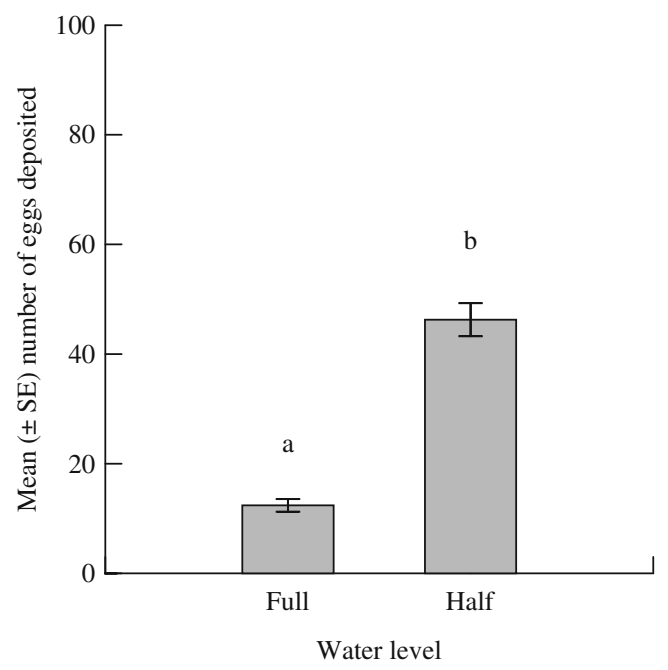

Fig. 5 Mean ( \pm SE) number of eggs laid by Ae. albopictus in containers fully- and half-filled with water. Bar charts with the same letter or number do not show a significant difference $(P<0.05)$
2003). Similarly, the disturbance of the water surface due to falling raindrops may increase energy loss by the larvae, as they attempt to escape from the effects of rain drops when they come to the water surface for oxygen (Paaijmans et al. 2007). These factors could reduce the fitness of the larvae, pupae, and the emerging adults. On the other hand, the removal of some larvae by raindrops during heavy rains results into reduced competition for food, thus increasing body size at emergence and fitness of the larvae remaining in the container. However, in areas with high rainfall, since the field populations of developing larvae are exposed to frequent rains, such positive effects are more unlikely.

Once a female mosquito becomes gravid, it goes through a period of oviposition site seeking. Ae. albopictus females were shown to elicit increased egg retention under lowmoisture conditions (Rahman et al. 2010) and decreased egg deposition in the presence of oviposition deterrents (Xue et al. 2001) and food scarcity (Dieng et al. 2002). In Japan, females of Ae. aegypti were reported to deposit eggs preferentially in open-type tree holes (Tsuda et al. 1994) to protect larvae during drought. This behavior could be an adaptation to prevent unsuccessful egg development and better survival of the species. In our study, it was observed that Ae. albopictus females preferred to lay eggs in halffilled containers. During rainfall, the overflow events tend to occur more rapidly in fully filled containers than in halffilled ones. Since overflow has direct detrimental effects on mosquito larvae through splashing out, Ae. albopictus may avoid fully filled containers for oviposition. Paaijmans et al. 
(2007) observed increased mortality and flushing out of immature stages of An. gambiae. With reference to these observations, it seems likely that Ae. albopictus females respond to their habitat overflow potential, with respect to its suitability for larval development. The observed increased egg deposition in half-filled containers could likely be an adaptation adopted to prevent the loss of their immature stages, since habitat overflow has a negative effect on survival (Paaijmans et al. 2007).

The flushing out of immature stages from containers by tap water from shower heads was used to mimic flushing out by rainfall larvae. Strong water input by rainfall, which provokes increased frequency of overflow events, would tend to decrease the probability of larval development completion. With frequent overflowing events, larvae have a higher probability of decreased lifespan, as feeding activities would be interrupted, thus reducing feeding rates. Since such a phenomenon is dependent on the size of droplets of water and the pressure and velocity of the droplets, the lack of consideration of these physical properties could be considered a drawback of our approach.

\section{Conclusion}

Heavy rains resulted in high Ae. albopictus larval and pupal loss, especially from small containers. Ae. albopictus, which prefer to lay eggs in partly filled containers rather than fully filled containers. These effects may limit the population size of the adults - the stage that vectors diseases. This study used simulated rainfall using tap water. However, we did not take into consideration the difference in quality between tap water and rainwater because our experiment was focused on the mechanical effects of rainfall on larval population dynamics. Additional studies are required to demonstrate whether or not the physical properties of our artificial rainfall were equivalent to those of real rain.

Acknowledgments We thank the team of the Vector Control Unit of the School of Biological Sciences, Universiti Sains Malaysia. The authors are grateful to the students for their assistance during experiments. This research was partially funded by grants 07-05-16MG1-GMB15 and 1001/PBIOLOGI/842004.

\section{References}

Ahmad F, Ahmad SY, Farooqi MA (2006) Characterization and geotechnical properties of Penang residual soils with emphasis on landslides. Am J Environ Sciences 2:121-128

Burke DS, Monath TP (2001) Flaviviruses. In: Knipe DM, Howley PM, Griffin DE, Lamb RA, Martin MA, Roizman B (eds) Fields' virology, vol. 1. Lippincott Williams \& Wilkins, Philadelphia, pp 1043-1126

Clements AN (1963) Physiology of mosquitoes. Pergamon, New York
Delatte H, Gimonneau G, Triboire A, Fontenille D (2009) Influence of temperature on immature development, survival, longevity, fecundity and gonotrophic cycles of Aedes albopictus (Skuse), vector of chikungunya and dengue in the Indian Ocean. J Med Entomol 46:33-41

Dieng H, Mwandawiro C, Boots M, Morales RM, Satho T, Tuno N, Tsuda Y, Takagi M (2002) Leaf litter decay process and the growth performance of Aedes albopictus larvae. J Vect Ecol 2:31-38

Dieng H, Boots M, Tsuda Y, Takagi M (2003) A laboratory oviposition study in Aedes albopictus (Diptera: Culicidae) with reference to habitat size, leaf litter and their interactions. Med Entomol Zool 54:43-50

Dieng H, Boots M, Tuno N, Tsuda Y, Takagi M (2006) A laboratory and field evaluation of Macrocyclops distinctus, Megacyclops viridis and Mesocyclops pehpeiensis as control agents of the dengue vector Aedes albopictus in a peridomestic area in Nagasaki, Japan. Med Vet Entomol 16:285-291

Dieng H, Satho T, Eshita Y (2007) The effects of male on the blood feeding behavior of the dengue vector Aedes albopictus (Diptera: Culicidae): Implications for the laboratory oral feeding of Aedes vectors. Jpn J Environ Entomol Zool 18:17-22

Fish D, Carpenter SR (1982) Leaf litter and larval mosquito dynamics in tree-hole ecosystems. Ecology 63:283-288

Foo LC, Lim TW, Lee HL, Fang R (1985) Rainfall, abundance of Aedes aegypti and dengue infection in Selangor, Malaysia. Southeast Asian J Trop Med Public Health 16:560-568

Gratz NG (2004) Critical review of the vector status of Aedes albopictus. Med Vet Entomol 18:215-227

Hawley WA (1988) The biology of Aedes albopictus. J Am Mosq Contr Assoc 4(suppl 1):1-40

Hill J, Lines J, Rowland M (2006) Insecticide treated nets. Adv Parasitol 61:77-128

Hornby JA, Moore DE, Miller TW Jr (1994) Aedes albopictus distribution, abundance, and colonization in Lee County, Florida, and its effect on Aedes aegypti. J Am Mosq Contr Assoc 10:397402

Koenraadt CJ, Harrington LC (2008) Flushing effect of rain on container-inhabiting mosquitoes Aedes aegypti and Culex pipiens (Diptera: Culicidae). J Med Entomol 45:28-35

Konishi E (1989) Susceptibility of Aedes albopictus and Culex tritaeniorhynchus collected in Miki City. Japan to Dirofilaria immitis. J Med Entomol 26(420-424):423

Lo EKC, Narimah A (1984) Epidemiology of dengue disease in Malaysia, 1973-1982. J Malays Soc Health 4:27-35

Madon MB, Hazelrigg JE, Shaw MW, Kluh S, Mulla MS (2003) Has Aedes albopictus established in California? J Am Mosq Contr Assoc 19:297-300

Malavige GN, Fernando S, Fernando DJ, Seneviratne SL (2004) Dengue viral infections. Postgrad Med J 80:588-601

Mitchell CJ (1991) Vector competence of North and South American strains of Aedes albopictus for certain arboviruses: a review. $\mathrm{J}$ Am Mosq Control Assoc 7:446-451

Mitchell CJ, Haramis LD, Karabatsos N, Smith GC, Starwalt VJ (1998) Isolation of La Crosse, Cache Valley, and Potosi viruses from Aedes mosquitoes (Diptera: Culicidae) collected at used-tire sites in Illinois during 1994-1995. J Med Entomol 35:573-577

Paaijmans KP, Wandago MO, Githeko AK, Takken W (2007) Unexpected high losses of Anopheles gambiae larvae due to rainfall. PLoS ONE 2(11):e1146

Rahman GMS, Dieng H, Abu HA, MR. Che Salmah MR, Satho T, Boots M, Sazaly A (2010) The effects of moisture on the oviposition behaviour and larval eclosion of Aedes albopictus. $\mathrm{J}$ Am Mosq Control Assoc 26:373-380

Roiz D, Rosà R, Arnoldi D, Rizzoli A (2010) Effects of temperature and rainfall on the activity and dynamics of host-seeking Aedes 
albopictus females in northern Italy. Vector-Borne Zoonotic Dis 10(8):811-816. doi:10.1089/vbz.2009.0098.

Rozilawati H, Zairi J, Adanan CR (2007) Seasonal abundance of Aedes albopictus in selected urban and suburban areas in Penang, Malaysia. Trop Biomed 24:83-94

Simard F, Nchoutpouen E, Toto JC, Fontenille D (2005) Geographic distribution and breeding site preference of Aedes albopictus and Aedes aegypti (Diptera: Culicidae) in Cameroon, Central Africa. J Med Entomol 42:726-731

Shroyer DA (1986) Aedes albopictus and arboviruses: a concise review of the literature. J Am Mosq Control Assoc 2:424-428

Strickman D (1980) Stimuli affecting selection of oviposition sites by Aedes vexans (Diptera: Culicidae): moisture. Mosq News 40:236-245
Sota T, Mogi M, Hayamizu E (1992) Seasonal distribution and habitat selection by Aedes albopictus and Ae. riversi (Diptera: Culicidae) in northern Kyushu, Japan. J Med Entomol 29:296-304

Systat $^{\circledR} 13$ software (2009) Systat 13 for windows: Statistics. SPSS Inc, Chicago

Tsuda Y, Takagi M, Wada Y (1994) Ecological study on mosquito community in tree holes in Nagasaki, Japan, with reference to Aedes albopictus (Diptera: Culicidae). Jpn J Sanit Zool 45:103-111

Xue RD, Barnard DR, Ali A (2001) Laboratory and field evaluation of insect repellents as oviposition deterrents against the mosquitoes, Aedes albopictus. Med Vet Entomol 15:126-131

Zakaria R, Mansor A, Fadzly N, Rosely N, Mansor M (2009) Comparison of plant communities at six study plots in Penang forest reserves, Malaysia. Trop Ecol 50:259-265 